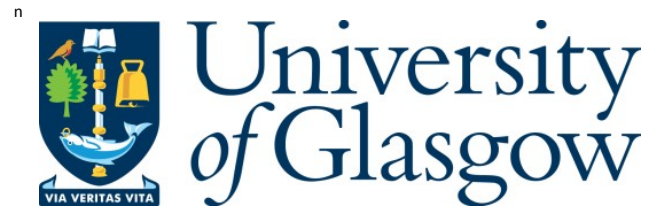

Cowan, R. (2015) Clarifying ethical intuitionism. European J ournal of Philosophy, 23(4), pp. 1097-1116.

There may be differences between this version and the published version. $Y$ ou are advised to consult the publisher's version if you wish to cite from it.

http://eprints.gla.ac.uk/100674/

Deposited on: 18 December 2014

Enlighten - R esearch publications by members of the U niversity of Glasgow http://eprints.gla.ac.uk 


\section{Clarifying Ethical Intuitionism}

\section{Robert Cowan}

In recent years there has been a resurgence of interest in Ethical Intuitionism, whose core claim is that normal ethical agents can and do have non-inferentially justified first-order ethical beliefs. Although this is the standard formulation, there are two senses in which it is importantly incomplete. Firstly, ethical intuitionism claims that there are non-inferentially justified ethical beliefs, but there is a worrying lack of consensus in the ethical literature as to what non-inferentially justified belief is. Secondly, it has been overlooked that there are plausibly different types of non-inferential justification, and that accounting for the existence of a specific sort of non-inferential justification is crucial for any adequate ethical intuitionist epistemology. In this context, it is the purpose of this paper to provide an account of noninferentially justified belief which is superior to extant accounts, and, to give a refined statement of the core claim of ethical intuitionism which focuses on the type of noninferential justification vital for a plausible intuitionist epistemology. Finally, it will be shown that the clarifications made in this paper make it far from obvious that two intuitionist accounts, which have received much recent attention, make good on intuitionism's core claim. 
In recent years there has been a resurgence of interest in Ethical Intuitionism (e.g., Audi (2004), Bedke (2009), Huemer (2005), Shafer-Landau (2003), Stratton-lake (2002)). Despite the moniker, intuitionism does not require the view that intuition (whatever that may be) is the source of all justified ethical belief and knowledge ${ }^{1}$. Here is the core claim:

Ethical Intuitionism (EI): normal ethical agents can and do have noninferentially justified first-order ethical beliefs ${ }^{2}$.

Although this is the standard formulation (an analogous formulation can be given for knowledge), there are two senses in which EI is importantly incomplete as a statement of ethical intuitionism. Firstly, EI claims that there are non-inferentially justified ethical beliefs, but there is a worrying lack of consensus in the ethical literature as to what non-inferentially justified belief amounts to, e.g., differing accounts from Sinnott-Armstrong (2006), Audi (2008). Secondly, it has been overlooked that there are plausibly different types of noninferential justification, and that accounting for the existence of a specific sort of noninferential justification is crucial for any adequate ethical intuitionist epistemology.

In this context, it is the purpose of this paper to provide an account of non-inferentially justified belief which is superior to extant accounts, and, to give a refined statement of the core claim of ethical intuitionism which focuses on the sort of non-inferential justification vital for a plausible intuitionist epistemology. In the final section, some possible implications of these refinements are discussed. Specifically, it will be shown that the clarifications made in this paper make it far from obvious that two intuitionist accounts, which have received much recent attention, make good on intuitionism's core claim. 


\section{Non-inferentially Justified Belief}

Ethical intuitionists claim that some ethical beliefs are non-inferentially justified. When considering the distinction between non-inferentially justified belief and inferentially justified belief it is initially plausible that there is some relation between these and the psychological notion of inference. On one view, to engage in an inference is to proceed through 'a kind of passage of thought from one or more propositions to another, in part on the basis of a sense of some support relation between the former and the latter' (Audi, 2008: 485) ${ }^{3}$. With this in mind, at least three possible distinctive features of non-inferentially justified belief emerge: (1) non-inferentially justified beliefs cannot be inferred ${ }^{4},(2)$ non-inferentially justified beliefs are not or need not actually be ${ }^{5}$ inferred, and (3) non-inferentially justified beliefs are justified independently of an ability to infer them.

In what follows I will reject (1) and both versions of (2) as plausible accounts of noninferential justification, before defending (3) against a recent objection from Tropman (2011). Despite being able to survive this objection, I will reject (3) on other grounds, and defend an improved account of non-inferentially justified belief. Given this improved account, it will become clear that, contrary to initial appearances, there is not an interesting connection between the non-inferential/inferential justification distinction and the psychological notion of inference ${ }^{6}$.

Firstly, let us briefly consider (1):

Non-Inferential (1): $S$ has a non-inferentially justified belief that $p$ iff $S$ has a justified belief that $p$ and cannot infer $p$ from other propositions. 
Although it is difficult to think of counterexamples to the sufficiency claim of this account, the necessary claim of (1) should be rejected. To see why, consider the following example: suppose that upon listening to the finale of a piano recital, Melanie comes to have a noninferentially justified perceptual belief (let's say, as the result of auditory experience) that that is a C\# minor chord, and that subsequently, the pianist informs her that they did indeed end by playing a $\mathrm{C} \#$ minor chord. It now seems that, were Melanie to listen to the performance again, she would have the ability to infer that the pianist was playing a $\mathrm{C \#}$ minor chord (based on testimony). Nevertheless, it would be odd if Melanie were now disbarred from having a non-inferentially justified belief in the proposition in question. Epistemic overdetermination is compatible with non-inferential justification. Hence, the necessary claim is false.

One might be tempted to draw the following lesson from the failure of (1): what made Melanie's belief non-inferentially justified in the first place was that it wasn't actually inferred when formed. This brings us to the weaker account (2):

Non-Inferential (2): $S$ has a non-inferentially justified belief that $p$ iff $S$ 's belief that $p$ is justified and $S$ hasn't inferred $p$ from other propositions.

On a simple understanding of inference, where this involves some sort of consciously explicit reasoning process, the sufficiency claim of (2) appears false (note that the following objection applies to the sufficiency claim of the weaker version of (2): $S$ has a non-inferentially justified belief that $p$ iff $S$ 's belief that $p$ is justified and $S$ need not actually infer $p$ from other propositions $)^{7}$. This is because it is highly plausible that there are at least some justified beliefs that may have been arrived at in a consciously non-inferential manner, but where we would be reluctant to say that such beliefs are epistemically non-inferential, e.g., 
Proton: Upon observing a vapour trail in a cloud chamber, Martha the physicist non-inferentially forms the belief that that is a proton.

Martha's belief is formed in a psychologically non-inferential way. However, on the assumption that Martha's visual experience does not have any proton content, to be justified in believing that that is a proton it seems that Martha requires the presence of justified ancillary beliefs linking vapour trails in cloud chambers to the presence of protons. That is, in the absence of these sorts of justified beliefs, her proton belief would fail to be justified. Why think that this makes Martha's belief inferentially justified? The answer is that noninferentially justified beliefs are supposed be those which are capable of halting the epistemic regress of justification. However, if Martha requires other justified beliefs to be justified in believing that that is a proton, then it seems that the regress has not been halted, as there remains the question of where these ancillary beliefs derive their justification from.

One might accept this but query why we ought to think that Martha's belief really does depend for its justification on other justified beliefs. The answer is that it is highly plausible that beliefs about protons are not the sorts of things which are candidates for being the foundations of our justified belief/halting the epistemic regress of justification, at least not for beings like $u s$, with our cognitive capacities and limitations. The same might be said for other propositions which are - intuitively, at least - not plausible candidates for non-inferential justification: e.g., there are 5,280 feet in a mile, bats are more closely related to primates than to rodents, the fall of the Roman Empire was caused partly by the military's having too much influence on the government ${ }^{89}$.

At this point, someone might try to defend (2) by widening the notion of inferred ${ }^{10}$. The relevant move would be to make the following conjunctive claim: in the case of Proton, 
Martha's proton belief is based upon the conjunction of her perceptual experience and some general background belief(s) linking vapour trails with the presence of protons (where to base a belief on some other belief or non-doxastic state is - roughly - for the latter belief or state to be both the cause and reason for the formation of the former ${ }^{11}$ ), and, if a belief is based upon another belief (even partly) then this counts as an inference, albeit an implicit or tacit one. Given this amendment (2) would - correctly - identify Martha's proton belief as inferentially justified because it involves an implicit inference. In her (2011), Tropman seems to suggest something like this line of thought:

\begin{abstract}
we can base a belief on another without consciously rehearsing an inference between the two. Yet, when one belief is held on the basis of a reason [a belief], this belief is inferential in a sense that does not require the believer to work thorough an explicit reasoning process. If a person believes that $p$ on the basis of her belief that $r$, this means that the person takes $r$ as evidence of $p$. Not only does the person have the necessary beliefs to construct an explicit inference to the conclusion that $p$, but it seems that she has already made, tacitly, such an inferential connection among her beliefs. ((my italics) (Tropman, 2011:362)
\end{abstract}

Although this account apparently constitutes an improvement on the original version of (2), the new sufficiency claim is also false (as before, the following objection also applies to the sufficiency claim of the weaker account: $S$ has a non-inferentially justified belief that $p$ iff $S$ 's belief that $p$ is justified and $S$ need not actually infer $p$ from other propositions). To see why, note that accounting for inferential justification in terms of explicit or implicit inference (where the latter is at least partly cashed out in terms of a basing relation between beliefs) is hostage to it being the case that in possible cases human agents do in fact base their beliefs on other beliefs in the relevant cases. Now consider the following amendment of Proton: suppose that Martha hasn't actually formed any beliefs linking cloud chambers, vapour trails, 
and protons. Imagine instead that it merely seemed (intellectually) ${ }^{12}$ to Martha that there was some link between these, and that this non-doxastic state was a partial basis (in conjunction with her perceptual experience) for her belief that that is a proton. In this case Martha's belief is not based upon another belief, and hence doesn't involve a tacit inference, yet her justification still seems to be inferential, e.g., she requires justification for believing propositions other than that is a proton. Certainly, she will likely be disposed to form beliefs about cloud chambers and protons and to draw the relevant inference(s) to her proton belief ${ }^{13}$, but in this case she has not inferred her belief in any reasonable sense of the notion. Hence, the amended (2) is false. Note, however, that the necessary claim of (2) may still be true.

From the failure of (2) we have learnt that a subject need not have actually inferred a belief or based it upon some other belief in order for it to be inferentially justified. We may, however, still want to maintain that there is some relation between, on the one hand, the psychological notion of inference (either explicit or implicit), and on the other, the epistemological distinction between non-inferential and inferential justification. In light of this, we might try to amend the account such that for a belief that $p$ to be justified non-inferentially it is justified independently of the ability to infer $p$ (either explicitly or implicitly ${ }^{14}$ ) from other propositions. Hence, the following influential account of non-inferential justification associated with the work of Sinnott-Armstrong (2006), (2007):

Non-Inferential (3): $S$ has a non-inferentially justified belief that $p$ iff $S$ has a justified belief that $p$ and $S$ 's belief is justified independently of an ability to infer $p$ from other supporting propositions they have justification for believing.

Plausibly, (3) is able to handle the amended Proton example where Martha hasn't based her belief on other beliefs; (3) accounts for the justification that Martha has for her proton belief 
at least in part by her ability to infer it from other propositions she has justification for believing, e.g., about the relation between protons, vapour trails, and cloud chambers. Were Martha to lack this ability, the proponent of (3) will claim that she doesn't have justification for believing $p$. Hence, (3) correctly predicts that Martha's justification is inferential.

Despite apparently constituting an improvement on (2), this account has recently been criticised by Tropman (2011) who appears to doubt that any belief could be justified (inferentially or non-inferentially) independently of an ability to infer it. In what follows, I will argue that Tropman's argument against (3) fails, but will ultimately go on to suggest that the account faces problems, and that we ought to adopt an alternative to (3).

Tropman's basic line of thought against (3) is that an ability of a subject to infer a proposition (where this includes just about any type of inference: deductive, inductive, statistical, enthymematic etc) from other propositions could plausibly be required to have justification for believing any proposition. However, this is not because all of our beliefs are justified by this sort of ability, but because the possession of this sort of ability is an enabling condition of justification. As she says 'being able to draw an inference to a belief might be a minimal condition for being justified in believing it, even if this inferential ability is not what justifies the belief' (Tropman, 2011: 360). Tropman illustrates her point by considering the claim made by some ethical intuitionists, e.g., Audi (2004), (2008), that adequately understanding self-evident propositions non-inferentially justifies belief in them:

Suppose an agent believes a moral truth that is self-evident... Suppose further that she is completely unable to form any inference whatsoever to the truth in question. In such a case, one might reasonably conclude that she did not adequately understand the 
relevant moral claim in the first place. Take the following moral truth, a truth that Audi [ethical intuitionist] thinks is self-evident: It is prima facie right to keep one's promises. Consider now the number of inferences that one could draw to the moral claim in question: 'Keeping one's promises involves being truthful, and we morally ought to be truthful, so we have a prima facie duty to keep one's word'; 'Sally is a very moral person, and she keeps her promises, so promise-keeping is the moral thing to do'; 'we morally ought to keep promises because breaking them lacks virtue (or is disrespectful or is against the law of contradicts God's will)'... the ability to draw at least some of the above kinds of rationalising arguments for the morality of promisekeeping is plausibly part and parcel with grasping adequately the moral proposition in question. (Tropman, 2011: 360-1)

This idea of an enabling condition might be understood by analogy with the claims that moral particularists, e.g., Dancy (2003), make about reasons, e.g., that a promise was not made under duress might be an enabling condition for an act's being the keeping of a promise to constitute a moral reason for action, but not itself a reason for action. In summary: Tropman is claiming that (3) should be rejected because there are no beliefs (ethical or non-ethical) that are justified independently of an ability to infer them. This is true, even though some beliefs are not justified by this ability.

In order to assess the plausibility of Tropman's argument we should consider the question of why having this sort of ability would be an enabling condition for having a justified belief. It might seem reasonable to interpret Tropman as having something like the following thought in mind: having an ability to infer from other propositions is required because this sort of ability is 'part and parcel' of understanding propositions that we believe. If one doesn't possess this ability, then one doesn't understand the proposition, and one surely can't be justified in believing a proposition one doesn't understand. 
In order to see why this ultimately fails as an objection to (3), consider firstly the following point: under the present interpretation Tropman thinks that the ability to draw inferences is required for understanding, but it is not at all obvious that the sorts of inferences that Tropman has in mind - from other propositions that the agent has justification for believing are part and parcel of understanding the proposition in question. To bring out this point more clearly, consider the distinction that Audi (1999) draws between inferences from (so-called internal inferences) and inferences to (so-called external inferences) a proposition, where only the former are associated with an understanding of the proposition in question. Here is an illustration of internal inference:

[consider] the proposition that the existence of great grandchildren entails that of four generations of people. One might see the truth of this by noting that by definition great grandchildren are three generational removes from their great grandparents and that this requires the existence of one additional generation, hence four. Here the partly definitional proposition noted is a potential ground for believing the self-evident proposition, but the inference can still be considered internal because this ground is accessible by simple conceptual understanding of the original proposition. (Audi, 1999: 218)

The point of interest here is that the examples Tropman gives of inferences required for understanding are all inferences to the proposition (indeed she explicitly uses this sort of language: 'Consider now the number of inferences that one could draw to the moral claim in question'), and it is not at all obvious that these are plausibly required in order to be said to possess understanding. To make it more plausible, Tropman's claim should be amended such that an ability to make internal inferences is a sort of enabling condition for justification. However, it is now hard to see how this does conflict with (3), since the claim made there is that non-inferentially justified belief is that which is independent of an ability of $S$ to infer 
that $p$ from other propositions, and it is not obvious that the propositions involved in internal inferences get to count as other propositions (in the relevant sense) if they are "partly definitional'. Hence, if this was the intended point, it fails to cause problems for the account of non-inferentially justified belief under consideration ${ }^{15}$.

Given that the requirement of an ability to draw internal inferences does not seem to be incompatible with (3), in order to constitute an objection Tropman would need to show that external inferences of the sort that she describes, e.g., "Sally is a very moral person, and she keeps her promises, so promise-keeping is the moral thing to do', are required in order to possess understanding of a proposition, e.g., acts of promise keeping are prima facie right. Aside from being unintuitive, there remains the serious task of providing an account of which external inferences are required for understanding a particular proposition, $p$. The alternative would be to say that external inferences are required but to impose no limits on what these might be. However, on this second account it becomes puzzling as to why such an ability is necessary for understanding a particular proposition (and hence enabling justification for belief), $p$, since the inferences that enable one to be justified in believing that $p$ could feasibly be the same as those required to understand some completely (semantically) unrelated proposition, $r$. This is an odd result ${ }^{16}$. Hence, the burden of proof is on Tropman to provide an account of specifying the external inferences required for understanding.

Briefly, here is an attempt to discharge this burden that ultimately doesn't work. If we limit discussion to the ethical domain there may indeed be a sense of understanding which requires the ability to draw external inferences. Consider a view similar to that held by Hopkins (2007) and Hills (2009) that the goal of ethical thinking is to attain an ethical understanding, where an understanding is not basic semantic comprehension but instead involves a grasp of 
the ethical reasons that make one's ethical judgments true, e.g., that an action was wrong because it involved causing needless suffering ${ }^{17}$. On this sort of view, it might be plausible to posit the existence of a norm of belief governing ethical discourse; namely, that one needs to have a grasp of the reasons that make an ethical judgment true in order to be entitled to hold that belief, even if one has justification for the belief independently of this grasp.

In this context, Tropman may want to claim that an ability to draw external inferences to one's ethical judgment about the reasons why one's ethical belief is true is an enabling condition for justification. This is because such an inferential ability might be required for ethical understanding. However, there is an important dissimilarity between this and the account just sketched. Whereas on the latter view a norm plausibly governs entitlement to form justified beliefs but not justification, Tropman's account would appear to imply that such a norm governs the existence of justification itself. But that sounds like all justification is inferential. Given this, Tropman would need to explain how such external inferences are merely enabling conditions and don't introduce some sort of inferential epistemic dependency ${ }^{18}$.

In lieu of an improved account, Tropman's challenge to (3) fails. Notably, ethical intuitionists such as Audi appear to agree that an ability to infer is not an enabling condition of justification, e.g., '[an] ability to infer a proposition is not a general requirement for justifiedly believing it' (Audi, 2007: 204).

Despite surviving this challenge it will now be argued that we have reason to reject (3). This is because the concomitant account of inferential justification is inadequate. After having explained this point, I will briefly present an improved account of non-inferential justification. Interestingly, on this account, there does not seem to be an interesting 
connection between the non-inferential/inferential justification distinction and the psychological notion of inference (explicit or implicit).

To see why, consider the concomitant account of inferential justification we get if we accept (3): inferentially justified beliefs are epistemologically dependent on an ability to infer them from other supporting propositions. Notice that, at least on the explicit sense of inference, this seems to suggest a focus on demonstrative justification, i.e., the ability to show that one is justified, rather than the state of being (inferentially) justified (cf. Shafer-Landau (2003)). However, in giving an account of inferential justification it seems to make more sense to say that someone who does in fact have justification for believing propositions that support $p$ will be inferentially justified in virtue of their commitment to these supporting propositions (even if this falls short of belief), rather than an ability to draw inferences (explicit or implicit) that reflect these commitments. In most cases it is of course plausible that subjects will be able to draw inferences (and we might admit that this is a clear sign that they are justified, the absence of which might make us doubt that the subject is in fact justified), but we might still doubt that it this ability that is doing the justificatory work in the case of inferential justification, as opposed to actually having justification for believing other propositions (and perhaps basing their belief on these propositional justifications). This suggests that we should reject (3) and adopt the following improved account of non-inferential justification:

Non-Inferential (4): $S$ has a non-inferentially justified belief that $p$ iff $S$ has a justified belief that $p$ and $S$ 's belief is justified independently of their justification for believing other supporting propositions ${ }^{19}$.

Assuming that (4) does constitute the most satisfactory account of non-inferential justification, the following points are worth noting: firstly, the notion of a supporting 
proposition is supposed to pick out a positive epistemic dependence, i.e., justification for believing supporting propositions is what justifies the belief in question ${ }^{20}$. Secondly, it remains agnostic as to whether justified beliefs are required to be based upon adequate propositional justifications for belief. Finally, the account suggests a detachment of inferential and non-inferential justification from the psychological notion of inference, i.e., inferential justification does not depend on actual inference, nor on the ability to make inferences (in either the explicit or implicit senses). Following from this, one might think that to call this inferential justification is a misnomer. If one is sympathetic to this thought then perhaps mediate justification ${ }^{21}$ is a more appropriate label, with immediate justification being the sort of justification that we associate with ethical intuitionism and halting the epistemic regress.

\section{Refining Ethical Intuitionism}

The standard statement of ethical intuitionism is that ordinary agents have at least some noninferentially justified first-order ethical beliefs. In the previous section it was argued that this is best understood as the claim that there are some ethical beliefs that don't depend for their justification on subject's having justification for believing other propositions (ethical or otherwise). However, as will now be shown, this is an incomplete statement of ethical intuitionism.

In order to begin to see this, consider that in general epistemology there is a reasonable degree of consensus that if anything is, the following are sources of non-inferential justification: perceptual experience, a priori intuition, introspection, and memory ${ }^{22}$. Despite this, no-one defends an ethical intuitionism that is based upon introspection or memory. This 
suggests that there may be more to the core claim of ethical intuitionism than is normally thought. Providing an explanation of why no-one defends these views will hopefully reveal what more there is to it.

Explaining the lack of an Introspective Intuitionism in contemporary ethical epistemology is relatively easy: introspection doesn't plausibly provide non-inferential justification for firstorder beliefs (ethical or otherwise) as EI requires ${ }^{23}$. Instead, the focus will be on an intuitionist view which assumes that memory is the source of non-inferentially justified beliefs, e.g., Audi (1998):

Memory Intuitionism (MI): normal ethical agents have non-inferentially justified ethical beliefs by remembering them.

It seems obvious that, by itself, Memory Intuitionism does not constitute a serious intuitionist epistemology, i.e., it is not a plausible independent account ${ }^{24}$. Explaining what, exactly, is wrong with MI is somewhat trickier. Two possible explanations of what is problematic about MI will be offered which will ultimately illuminate how best to construe ethical intuitionism. Getting there will require a consideration of two leading accounts of the epistemology of memory.

Firstly, many philosophers hold a Preservationist view about memory (e.g., Owens (2000), Senor (2007)), which roughly amounts to the view that the process of remembering $p$ or seeming to remember $p$ cannot generate justification for believing that $p$. Rather, memory can at best preserve a previous (non-memorial) justification that one had for $p$, even if the justification that one has in virtue of one's memory is non-inferential. Put another way, memory beliefs or memory seemings that $p$ are (positively) epistemically dependent on one having had some other justification for $p$, even if they are not dependent on there being 
justification for believing propositions other than $p$. Note that this essentially involves adopting an externalist account of memory justification, i.e., one which limits the role of consciously accessible internal factors vis-a-vis the justified status of a belief. This is because on the Preservationist view a subject may not be aware that the belief they have remembered is in fact unjustified (e.g., they may have forgotten that they formed it on the basis of wishfulthinking or on a whim), even though they might appear justified from their own subjective perspective.

Assume for now that Preservationism is the correct epistemology of memory. It seems that we have the following explanation of what is unsatisfactory about Memory Intuitionism: MI only gives us an account of how defeasible non-inferential justification for ethical belief can be preserved but not how it is generated. If MI were formulated such that our generative ethical justification is inferential, then one might reasonably think that this is a cheap or trivial sort of ethical intuitionism. Alternatively, if MI were amended so as to state that we have generative non-inferentially justified ethical beliefs, which we can be non-inferentially justified in believing when remembered, this would leave the account significantly incomplete: we would now want to know where the generative non-inferential justification for ethical beliefs is coming from.

Independently of the plausibility of Preservationism, there is a general lesson to be learnt from this account which will inform a refinement of what ethical intuitionism is. It seems that any satisfactory ethical intuitionism ought to account for the existence of non-inferentially justified ethical beliefs that are justified by generative sources, i.e., that are epistemically independent of having justification for believing the relevant propositions from other sources. Notice that this shifts the focus of our attention towards sources of justified belief, rather than 
justified beliefs themselves. Hence, the core claim of ethical intuitionism should be reformulated so as to read:

Ethical Intuitionism (EI): normal ethical agents can and do have epistemically independent non-inferential justification for first-order ethical beliefs.

Epistemic independence is being understood in contradistinction to epistemic dependency, which can be summarised thus:

Epistemic Dependency (ED): a state, $d$, epistemically depends on another state, $e$, with respect to content $c$ iff $e$ must be justified or justification-conferring in order for $d$ to be justified or justification-conferring with respect to content $c^{25}$.

With this refinement of ethical intuitionism in hand it is worth considering an alternative explanation of what is problematic about Memory Intuitionism. The previous explanation depended upon a particular Preservationist view of the epistemology of memory. However, some philosophers (Audi (1998), Schroer (2007)) endorse Memory Foundationalism, which claims that memory is in fact a generative source of justification i.e., memory is able to render beliefs justified without their having being justified by some other, intuitively more basic, source, e.g., perception. Note that proponents of this view tend to endorse a reasonably strong sort of internalism about justification, whereby justification is determined by 'internal' factors of individuals, e.g., mental states like beliefs or appearances. On this conception, individuals who are 'internally' identical to us, but are unfortunate enough to inhabit a Cartesian Demon world (where we there is little or no knowledge of the external world), could still have justified beliefs. 
Even if this were the correct account of the epistemology of memory, it seems that Memory Intuitionism should still not be taken seriously. To see why this is true, consider the nonethical analogue of Memory Intuitionism, i.e., we have non-inferentially justified non-ethical beliefs in virtue of memory. In this case it seems that merely positing the justificationconferring powers of memory would be insufficient as an account or explanation of how we have knowledge of the external world. Memory is the wrong sort of state to posit as hooking us up to a mind-independent external reality in a way that is plausibly required for knowledge. A similar point can be made about the ethical case; merely positing memory as the source of non-inferentially justified belief seems inadequate because it is not a plausible candidate for the sort of thing that would, by itself, connect us to a mind-independent ethical reality ${ }^{26}$. More specifically, memory does not constitute what Prichard (1912) referred to as an 'act of moral thinking' or what Väyrynen (2008) refers to as 'substantive ethical thought' where these terms are to be taken as picking out processes or states that perform a similar functional role as perceptual experiences do vis-a-vis our justified empirical beliefs, which we pre-theoretically regard as sources of knowledge.

Notice that we need not think that Memory Foundationalism is a plausible epistemology of memory in order to learn something about what is required of a plausible ethical intuitionism. For it seems that any plausible ethical intuitionist account ought to explain the existence of epistemically independent non-inferential justification in terms of a process or state which can plausibly be construed as hooking us up to a mind-independent ethical reality, i.e., as involving substantive ethical thought. Hence, the core claim of ethical intuitionism ought to be reformulated: 
Ethical Intuitionism (EI): normal ethical agents can and do have epistemically independent non-inferential justification for first-order ethical beliefs that is the result of substantive ethical thinking.

\section{Implications?}

Having provided an account of non-inferential justification, and a refined statement of the core claim of ethical intuitionism, this final section will briefly consider the implications for two extant accounts which have received a good deal of recent attention: Affectual Intuitionism and Perceptual Intuitionism. For purposes of space, the discussion will be short and of a broad-brush nature, but is suggestive of future development.

Consider the following account which is endorsed by some contemporary intuitionists, e.g., Roeser (2011):
Affectual Intuitionism (AI): normal ethical agents have non-inferential justification for first-order ethical beliefs in virtue of emotional experiences.

For AI to constitute a plausible independent account of ethical intuitionism, the noninferential justification provided by emotional experience needs to be of an epistemically independent sort (let's just assume that emotions do involve something like an 'act of moral thinking').

Here is one reason to think that emotional experiences are (positively) epistemically dependent: on one plausible view of the emotions, e.g., see Brady (2011), Goldie (2004), emotional experiences are best understood as non-doxastic representational states which can, however, be justified or unjustified. Emotions can be justified or unjustified because they are, or ought to be, responsive to reasons, e.g., my acting lecherously at the party is a reason for 
me to feel guilty. With regard to the epistemology of emotions, it seems that one could reasonably take the view ${ }^{27}$ that, if they are to play any role in non-inferentially justifying evaluative or ethical beliefs, it is necessary that they are justified. Further, one might think that emotions are themselves justified only if they are had in response to justified or justification-conferring states about the presence of features of the world which make the emotional response justified, i.e., features that are reasons for the emotion. To illustrate; my guilt - with representational content that $I$ have acted wrongly - is justified only if it is had in response to justified or justification-conferring states about the presence of features of the world which make it appropriate for me to feel guilty, such as my lecherous behaviour at the party ${ }^{28}$. However, if this is the correct account of emotions and their epistemology (and note that it is not being endorsed here), then it seems that emotional experience is epistemically dependent in the way defined ${ }^{29}$. If so, then Affectual Intuitionism is not, by itself, an adequate intuitionist account.

Someone might object that the epistemic dependency in question is of a relatively innocuous sort. The thought would be that there is an important sense in which the putative justification one gets from one's emotional experience in these sorts of cases is generative, i.e., emotional experience generates justification for ethical belief where there was none, despite being epistemically dependent on having justification for believing other evaluative propositions. Note, however, that for this move to be legitimate, it seems to require that we can draw a sharp distinction between the evaluative and the ethical which may not be very plausible. In any case, even if there is a division between the two, it is not obvious that this sort of epistemic dependency really is innocuous from the point of view of ethical intuitionism. 
Affectual Intuitionism is potentially problematic due to an apparent epistemic dependence on justification for believing evaluative propositions. Consider now an account of intuitionism, which, at least on one particular interpretation, may involve an epistemic dependency on justification for believing ethical propositions. This would mean that it is, by itself, an inadequate account of ethical intuitionism since it doesn't make good on the core claim. The account in mind is the following ${ }^{30}$ :

Perceptual Intuitionism (PI): normal ethical agents have non-inferential justification for first-order ethical beliefs by having ethical perceptual experiences.

If true, PI would seem to constitute an a posteriori version of ethical intuitionism, providing an independent alternative to more popular a priori accounts, e.g., seemings and self-evidence accounts (see Huemer (2005) and Audi (2004)). Perceptual Intuitionism may therefore hold considerable attraction for ethical naturalists.

In recent discussions of PI (e.g., Väyrynen, (2008)), it has been assumed that in order for the view to get off the ground, the following non-epistemological view would have to be true:

Ethical Perception (EP): normal ethical agents can and do have perceptual experiences (at least some of which are veridical) as of the instantiation of ethical properties ${ }^{31}$.

Arguably, the most plausible way of making good on the central claim of EP is that ethical perception is an acquired capacity whose acquisition is facilitated by a process of cognitive penetration $^{32}$. An initial way of thinking about cognitive penetration is simply to understand it as grounding the idea that what a subject non-perceptually thinks can alter the way in 
which they perceptually experience the world, or that perception is 'theory-laden'. More specifically, a visual experience, $e$, is cognitively penetrated if the representational content and phenomenal character of $e$ are altered by states in the cognitive system, e.g., beliefs, concepts, desires, emotions, memories, imaginative states, intuitions, and where this does not merely involve those cognitive states having effects on the subject's visual attention. Further, if cognitive penetration is possible then the following scenario will be possible: two subjects could be attending to identical distal visual stimuli, $s$, whilst having different perceptual experiences, $e$ and $e^{*}$ due to differences in their cognitive economy. For example, suppose that I believe that John is angry but you don't. If cognitive penetration is possible, then upon seeing John, I may perceptually represent John's anger (because of my belief), while you do not because you lack the relevant belief. This is despite the fact that we are both attending to the same stimuli, e.g., John's facial features.

We can be more specific about the type of cognitive penetration plausibly involved in ethical perception. Firstly, we can consider the nature of the alteration to the content of perceptual experience brought about by states in the cognitive system. There are broadly two ways in which this might work: either cognitive penetration will involve the alteration or modification of already existing perceptual contents, or, it may involve the addition of perceptual contents to already existing contents. For an example of the first type of alteration: consider a study conducted by Delk and Fillenbaum (1965), and highlighted by Macpherson (2012), where it appears that the background beliefs of subjects about shapes that are characteristically red altered their perceptual experience when presented with these shapes; namely, they represented them as being more red than they actually were. For an example of the second type of alteration, it is plausible to think that someone who can identify pine trees by sight may perceive the same sorts of features that non-experts perceive, e.g., the leaves 
and branches etc., but because of their expertise their perceptual experience represents, in addition to these features, the property of being a pine tree $e^{33}$.

Although it will not be argued for here, it seems most plausible that ethical cognitive penetration, which involves a sort of perceptual expertise, will involve the addition of ethical perceptual contents to already existing non-ethical perceptual contents, without the modification of the latter. For example, two people - David and Martha - who are presented with the scene of hoodlums setting fire to a cat, may both perceive the very same non-ethical features, e.g., the screams of the cat, the laughter of the hoodlums etc, but because of Martha's ethical background beliefs, her perceptual experience represents, in addition to these features, the property of wrongness (prima facie or all things considered), while David's does not.

Cognitive penetration involves an etiological dependency of perceptual content on states in the cognitive system. To be more specific, two types of etiological dependency can be distinguished: firstly, there are apparently cases (see Delk and Fillenbaum (1965)) where subjects have had experiences of, e.g., a particular shade of red, due to cognitive penetration, but where those subjects do not generally require penetrating states with that sort of content in order to be in that type of perceptual state, e.g., they could have an experience of that shade of red without cognitive penetration. A stronger sort of dependency is exemplified in cases where the subject does generally require penetrating states with that type of content in order to be in a perceptual state with that content (see Macpherson (unpublished) for discussion). It seems that ethical cases of cognitive penetration will fall into the latter category, given the assumption that ethical perception is an acquired capacity. Indeed, more 
generally, we might think that cases of expert perception involve this strong etiological dependence because here cognitive penetration allows experts to see things that other people (non-experts) cannot ${ }^{34}$.

With this in mind, in the sorts of ethical cases that are of interest, the thought is that a subject's ethical beliefs, or some other cognitive states with ethical content, e.g., emotions, intuitions or concepts, could alter the way they perceptually experience the world such that they can literally see the world in a distinctively ethical way. For example, when presented with a scene of the torture of a cat, a subject's emotional experience of indignation or moral outrage (let's say, with something like the content that is wrong) might cognitively penetrate their perceptual experience such that, in addition to experiencing the scene of animal torture, their visual experience represents the wrongness of the animal torture.

The general point is that, on this view, having visual experiences with the sort of content apparently required to ground Perceptual Intuitionism is etiologically dependent upon the presence of the subject possessing other cognitive states with ethical contents. Supposing that EP is true, and is only true thanks to cognitive penetration, we can ask whether the justification conferred by ethical perceptual experiences confers epistemically independent non-inferential justification and involves substantive ethical thinking. Given space constraints it will not be possible to settle these questions here. Instead, the more modest goal will be to show that it is far from obvious that Perceptual Intuitionism really is, by itself, an adequate intuitionist account.

Focus first on the claim that ethical perceptual experiences confer epistemically independent non-inferential justification. Someone who denies this would essentially be holding some sort form of Preservationism about ethical perceptual experiences (brought about by cognitive 
penetration), i.e., the claim that ethical perceptual experiences are epistemically dependent on the justification-conferring powers of background cognitive states. To see why this might be plausible, consider the following example:

Proton*: Upon observing a vapour trail in a cloud chamber, Martha the physicist has a perceptual experience - the result of cognitive penetration by the belief that that is a proton - with the content that that is a proton. However, the background belief that penetrated her experience is unjustified, having being formed as a result of wishful-thinking.

Many will think it plausible that Martha doesn't get justification from her perception in this case, due to the unjustified status of her background belief ${ }^{35}$. Further, we might think that this holds even if Martha is not aware that her penetrating background state is unjustified. If that is right, then one might be tempted to adopt a Preservationist view about cognitively penetrated ethical experiences, i.e., they only justify if the penetrating state is justified or justification-conferring. If this is correct, then Perceptual Intuitionism is not, by itself, a plausible version of ethical intuitionism. Indeed, if we assume an analogous Preservationist view about memory, Perceptual Intuitionism will be about as epistemologically significant as Memory Intuitionism ${ }^{36}$.

Perhaps unimpressed by this example, or with Preservationism more generally, someone might claim that a Foundationalist view about ethical perceptual experience (including cognitively penetrated experiences of the sort under scrutiny) is more plausible ${ }^{37}$. This is the view that ethical perceptual experiences can justify beliefs, even if the penetrating states are not themselves justified or justification-conferring, and so would ground epistemically independent non-inferentially justified beliefs (note that this will be most happily allied with 
an internalist view about justification). However, even if this is correct, ethical perception needs to involve substantive ethical thought for it to fulfill the core claim of ethical intuitionism, i.e., it must be the right sort of state for hooking us up to a mind-independent ethical reality and grounding ethical knowledge.

The point of interest here is that, if the ethical contents of ethical perceptual experience are being brought about by other cognitive states via cognitive penetration, then it is far from obvious that ethical perception really does involve substantive ethical thought. Indeed, we might doubt that perception - construed in the way discussed - is how beings like us do substantive ethical thinking. To illustrate, consider a case where an ethical agent merely possesses the ethical concept of WRONGNESS and has engaged in no substantive ethical thinking. Assume also that the concept has little or no substantive content. If the concept were to penetrate the agent's experience such that they had a visual experience as of, e.g., the wrongness of animal torture, two possibilities present themselves: either the agent underwent some non-perceptual substantive ethical thinking, or else they didn't. In the latter case it seems that the agent has engaged in no substantive ethical thought. Instead, in cases of ethical perceptual experience it is more plausible to think that substantive ethical thinking is really being done elsewhere, e.g., in ethical reflection, emotion, or intuition, which then calls for an adequate account of their epistemological credentials. Hence, by itself, Perceptual Intuitionism may be inadequate, even on this alternative Foundationalist view ${ }^{38}$, and hopes for an independent a posteriori ethical intuitionism may be in jeopardy.

\section{Conclusion}


In this paper an improved account of non-inferentially justified belief and a refined statement of the core claim of ethical intuitionism have been offered. It was then shown that, once clarified and refined, whether an epistemological account can be regarded as grounding an adequate intuitionist epistemology is not as clear-cut as has been assumed ${ }^{39}$.

Robert Cowan

Philosophy

67-69 Oakfield Avenue

University of Glasgow

robert.cowan@glasgow.ac.uk 


\section{Notes}

${ }^{1}$ One possible exception to this is Huemer (2005).

2 This is what I take to be the core thesis of ethical intuitionism. The view has, however, been traditionally and contemporarily associated with metaphysical views, e.g., mind-independent ethical realism, ethical nonnaturalism and ethical pluralism. With the exception of mind-independent realism, I will be remaining agnostic on these ancillary views in this paper.

3 See also Sinnott-Armstrong (2011) for a similar account.

4 Note that one might wonder why anyone would hold this view. I admit that, given recent developments in epistemology, e.g., the work of Robert Audi which stresses that there is nothing suspect about beliefs being both inferentially and non-inferentially justified, it may no longer be even prima facie plausible. Having said that, there are two reasons to include discussion: (a) In his discussion of the self-evidence of the prima facie moral duties, W.D. Ross (2002), p. 30 says things which suggest that held something like this view of non-inferential justification, and, (b) Some contemporary discussions of intuitionism, e.g., Sinnott-Armstrong (2002), p. 310, slip into speaking in this way about non-inferential justification. Thanks to an anonymous reviewer for EJP for pressing me to justify the inclusion of NI (1).

5 Although these are different accounts, I class them together for the following reasons: (i) as will be shown, they face the same objections to their respective sufficiency claims, (ii) they are sufficiently similar that a separate treatment of both would needlessly complicate matters.

${ }^{6}$ As will become clear, this applies to both explicit and implicit inferences.

7 Interestingly, some might think that the necessary claim of (2) is also false. This would be because one agrees with Helmholtz (1962) that perception involves unconscious enthymematic inferences from what we might think of as raw experiential data to conscious perceptual experience that can play a justifying and rationalising role of belief and action, but yet maintains that perceptual experiences confer non-inferential justification. The natural line of response here for the defender of (2) is that these unconscious or subpersonal inferences aren't really inferences at all, but not everyone agrees on this matter. See Lyons, (2009) pp. 58-61 for discussion.

8 These examples are taken from Lyons (2009).

9 This point is subject to qualification. As will be suggested in $\S 2$, we can distinguish between different types of non-inferential justification; epistemically dependent and epistemically independent non-inferential justification. In the case of proton beliefs (and the others listed above), it is implausible to think that these are epistemically independent non-inferentially justified beliefs.

10 The view sketched here appears to be held by Audi (1998) and Tropman (2011).

${ }^{11}$ For some discussion of the basing relation in epistemology see Audi (1993) and Huemer (2007).

12 Contemporary intuitionists such as Audi (2008) and Huemer (2005) claim that intellectual seeming states can justify.

13 See Audi (1994) for the distinction between dispositions-to-believe and dispositional beliefs.

14 The distinction between explicit and implicit inferences drawn in the discussion of (2) should be kept in mind throughout the discussion of (3). Tropman's argument against (3) emphasises the explicit sense of inference. Note, that the points I go on to make for and against (3) are compatible with either notion.

15 One might think that the discussion has been unfairly limited to mere basic semantic understanding, and that the focus should instead be on what Audi (1999), (2004), refers to as adequate understanding, with the latter being presumably more robust. However, it is not clear that there is any substantial difference between the two. See 2004, pp. 49/50.

16 Given her apparent endorsement of the existence of self-evident truths, it seems that Tropman is not a semantic holist. 
17 One reason to think that this is correct comes from an apparently plausible view about ethical testimony. Roughly, the idea is that, although ethical testimony can plausibly transmit justification for belief to its recipients, there is still something normatively dubious about forming an ethical belief merely on the basis of someone else's say-so. The explanation of what is dubious about ethical testimony is that, in the relevant cases, ethical testimony does not provide the recipient with a grasp of the ethical reasons. Note, however, that this pessimist view about ethical testimony is not without its critics. See Sliwa (2012), Philosophical Studies, for an argument against pessimism. I am not endorsing pessimism about ethical or evaluative testimony. Rather, I am simply offering the view that understanding is the goal of ethical and evaluative thinking as a way (which ultimately fails) for Tropman to respond to my objections. Thanks to an anonymous reviewer for pressing me to be clearer about this.

18 There is at least one further possible epicycle. Tropman might alter her claim to be about entitlement to belief rather than justification (making her account like Hopkins'). However, she would then be faced with providing an account of why an external inferential ability might be required. This seems particularly important given that Hopkins himself allows that someone may be said to grasp ethical reasons, e.g., by having an ethical experience of their presence, and hence be entitled to their ethical belief, even if they can't articulate what they are (2007, p. 632). Tropman needs to occupy a stronger and seemingly implausible position.

19 Sinnott-Armstrong (2011) has suggested an updated account of non-inferential justification which seems to be compatible with (4).

${ }^{20}$ For discussion of negative epistemic dependency and its compatibility with non-inferential justification see Audi (1993)

21 See Pryor (2004) for an account of mediate justification that is very similar to mine. See also Väyrynen (2008) for a discussion of ethical intuitionism which refers to this alternative terminology.

22 A good deal less consensus surrounds the addition of emotion and testimony to this list. Also, naturalists will reject the inclusion of a priori intuition.

23 Of course, there is an inferential route from introspective beliefs to first-order ethical beliefs via the following sort of bridging principle (which would of course need to be justified): Most (all?) of the things that I believe are true.

24 On the assumption that testimony is a source of non-inferentially justified belief - see Audi (forthcoming) for this claim - a similarly problematic account would be Testimonial Intuitionism, i.e., Normal ethical agents have non-inferentially justified ethical beliefs by being told about them.

25 The notion of epistemic dependency comes from the work of Robert Audi. For a brief discussion of this in the context of ethical epistemology see his (1997), p. 117

26 See Depaul (1993) Ch.1 for a discussion of the No Contact With Ethical Reality objection to the epistemic powers of intuition.

${ }^{27}$ It seems that Goldie (2004) holds something like this view.

${ }^{28}$ It is not clear, exactly, what we or proponents of this sort of view ought to say about the epistemology of emotional experiences had in response to hypothetical cases.

29 Note that the epistemic dependency might be that associated with inferential or mediate justification, at least on my conception of this notion (see $\S 1$ ).

30 For discussion see especially Väyrynen (2008) and Audi (2010).

31 As is standard, the focus is on visual perception. A representationalist theory of perception is being assumed, i.e., (roughly) the view that to have a perceptual experience of an object $O$ as having a property $F$, is to be in a perceptual mental state with phenomenal character which represents $O$ as having the property $F$, i.e., has representational content $O$ is $F$.

32 For discussion, see Pylyshyn (1999), Siegel (2011), Macpherson (2012). 
${ }^{33}$ In a more specific terminology, it may involve the alteration of that which is represented as phenomenally present or involve the addition of phenomenally present as absent representation See, e.g., Macpherson (forthcoming) for this terminology.

${ }^{34}$ Thanks to an anonymous reviewer for EJP for pressing me to explain these points and distinctions in more detail.

${ }^{35}$ See Siegel (2012) for a similar sort of case.

${ }^{36}$ One possible disanalogy springs to mind. In the perceptual case, the contents of penetrating state may be more general than the content of the visual experience, e.g., content of penetrating belief is all torture is wrong, and the content of visual experience is that is wrong (or something like it). However, note that there is still epistemic dependency in both cases. Further, if the perceptual experiences are epistemically dependent on justified or justification-conferring states with a different content, then this would seem to suggest that the resultant justification is inferential or mediate.

${ }^{37}$ Note that this would seem to entail that Martha has non-inferential generative justification for the belief that that is a proton. Given earlier remarks this may seem like an implausible result.

${ }^{38}$ It seems that a similar point holds for the view that there are at least some cases where the penetrating states in ethical cognitive penetration aren't justified, but where we still ought to think that the perceptual experience is capable of justifying. 
39 Thanks to Michael Brady, Jennifer Corns, Fiona Macpherson, and an anonymous reviewer for EJP for helpful comments on earlier drafts of the paper.

\section{References}

Audi, R., 1997, Moral Knowledge and Ethical Character, Oxford University Press

Audi, R., 2004, The Good In the Right: A Theory of Intuition and Intrinsic Value, Princeton: Princeton University Press

Audi, R., 2008, Intuition, Inference and Rational Disagreement in Ethics, Ethical Theory and Moral Practice 11 (5): 475-492

Brady, M., 2011, Emotions, Perceptions and Reasons, in Bagnoli, C. (ed.), Morality and the Emotions, Oxford University Press

Delk, J. L. \& Fillenbaum, S. 1965 'Differences in Perceived Colour as a Function of Characteristic Colour,' The American Journal of Psychology, 78(2): 290-93.

Goldie, P., Emotion, Reason and Virtue, in Evans, D. \& Cruse, P. (eds.), Emotion, Evolution and Rationality, Oxford University Press

Hopkins, R., 2007, What's Wrong With Moral Testimony?, Philosophy and Phenomenological Research, 74 (3): 611-634

Hernandez, J.G., (ed.), 2011, The New Intuitionism, Continuum

Hills, A., 2009, Moral testimony and moral epistemology, Ethics 120 (1):94-127

Huemer, M., 2005, Ethical Intuitionism, Palgrave Macmillan

Lyons, J. C., 2009, Perception and Basic Beliefs: Zombies, Modules and the Problem of the 